\title{
The skin reflects: cutaneous lesions repairing the diagnosis of a systemic infection in an HIV-positive person
}

\section{Khadija Issoual, Hanane Bay Bay, Sara Dahhouki, Kaoutar Achehboune, Sara Elloudi, Zakia Douhi, Fatima Zahra Mernissi}

Departement of Dermatology, Hassan II Hospital University, Fez, Morocco

Corresponding author: Dr. Khadija Issoual, E-mail: khadijaissoual@gmail.com

Sir,

Cryptococcosis is a serious fungal infection with Cryptococcus neoformans, the most common systemic fungal infection during HIV infection [1]. We report the case of a cutaneous cryptococcosis revealing an HIV infection with systemic involvement.

An 27 year old patient, with a risky sexual behavior, she was admitted for a respiratory infection resistant to the usual treatments. during his stay in hospital, the evolution was marked by the installation of cutaneous lesions molluscum contagiusum like (Fig. 1), and the diagnosis of cryptococcosis was suspected then confirmed by mycological study of sputum, serology HIV was practiced returning positive. the evolution was fatal malgests the absence of neurological damage.

Cryptococcosis is a common infection during HIV infection, its tropism is mainly pulmonary, followed by cutaneous, bone and neurological involvement, the latter makes the prognosis [1-3]. The cutaneous involvement in cryptococcosis is characteristic allowing the diagnosis in presence of multi-systemic attack sometimes deceptive. The clinical lesion is made of umbilical papulo nodules molluscum contagiusum like $[1,4]$, evolving towards ulceration. Pulmonary involvement is diverse, from a simple cough to dyspnoea or respiratory failure, with nodular opacities or parenchymal infiltrates on radiography (Fig. 2) [1,2]; On the other hand, neurological involvement can be asymptomatic. It ranges from meningitis to

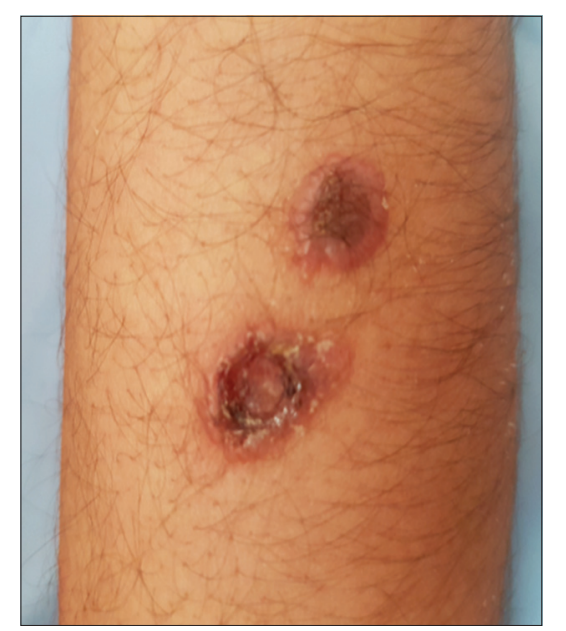

Figure 1: Clinical images showing multiple molluscum contagiosum-like lesions with necrotic pit in the center, in the forearm.

parenchymal abscesses, sometimes pseudo-tumoral aspects [5]. The diagnosis is mycological based on the direct examination and especially the culture, or on the skin biopsy $[1,6]$. An extension assessment is still essential, and the treatment is heavy, it uses the combination Amphotericin B and 5-Fluorocytosine in attack treatment then Fluconazole, followed by a maintenance treatment whose duration varies in immune status function [7].

The prognosis of the infection is usually severe; it is directly related to neurological involvement or disseminated forms. With a mortality of order of $20 \%$ in the pulmonary attacks, and $50 \%$ in the neurological ones, in spite of the antifungal treatments and the highly active antiretrovirals $[2,6,7]$.

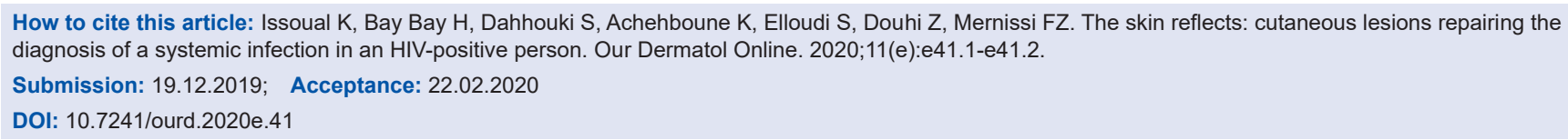




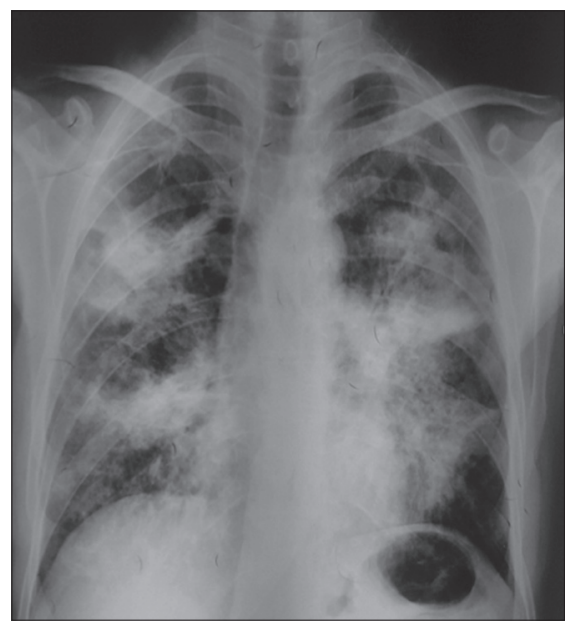

Figure 2: Chest radiography in a patient with pulmonary cryptococcosis showing a several asymmetrical bilateral hilar opacities crossed by air bronchograms.

Finally, our observation reflects the importance of the overall design of the patient in the canvas of the diagnostic research, in order to avoid the delay of the implementation of an adequate treatment, this can improve the prognosis of this affection which affects electively immunocompromised patients.

\section{Consent}

The examination of the patient was conducted according to the Declaration of Helsinki principles.

The authors certify that they have obtained all appropriate patient consent forms. In the form the patient(s) has/have given his/her/their consent for his/ her/their images and other clinical information to be reported in the journal. The patients understand that their names and initials will not be published and due efforts will be made to conceal their identity, but anonymity cannot be guaranteed.

\section{REFERENCES}

1. Kwon-Chung KJ, Sorrell TC, Dromer F, Fung E, Levitz SM. Cryptococcosis: clinical and biological aspects. Med Mycol. 2000;38 Suppl 1:205-13.

2. Perfect JR, Dismukes WE, Dromer F, Goldman DL, Graybill JR, Hamill RJ, et al. Clinical practice guidelines for the management of cryptococcal disease: update by the infectious diseases society of america. Clin Infect Dis. 2010;50:291-322.

3. Atarguine $\mathrm{H}$, Hocar $\mathrm{O}, \mathrm{Abbad} \mathrm{F}$, Rais $\mathrm{H}$, Idalene M, Tassi N, et al. Cutaneous cryptococcosis mimicking basal cell carcinoma and revealing systemic involvement in acquired immunodeficiency. J Mycol Med. 2015;25:163-8.

4. Béogo R, Andonaba JB, Bamba S, Konségré V, Diallo B, Traoré A. Cryptococcosis: a potential aetiology of facial ulceration. J Mycol Med. 2014;24:e185-8.

5. Kadjo K, Ouattara B, Adoubryn KD, Kra O, Niamkey EK. [Current aspects of neuromeningeal cryptococcosis in adults infected with HIV in the internal medicine service of the University Hospital of Treichville Abidjan (Cote d'Ivoire)]. J Mycol Med. 2011;21:6-9.

6. Bava AJ, Negroni R, Arechavala A, Robles AM, Bianchi M. Cryptococcosis associated with AIDS in the Muñiz Hospital of Buenos Aires. Mycopathologia. 1997;140:13-7.

7. Dromer F, Mathoulin S, Dupont B, Brugière O, Letenneur L, The French Cryptococcosis Study Group. Comparison of amphotericin $\mathrm{B}$ and fluconazole efficacy in the treatment of cryptococcosis in HIV-negative patients: retrospective analysis of 83 cases. Clin Infect Dis. 1996;22 Suppl 2:S154-60.

Copyright by Khadija Issoual, et al. This is an open access article distributed under the terms of the Creative Commons Attribution License, which permits unrestricted use, distribution, and reproduction in any medium, provided the original author and source are credited.

Source of Support: Nil, Conflict of Interest: None declared. 